\title{
Rheumatoid Factor and Anti Citrulinated Peptide. Relation with Remission and Progression in Rheumatoid Arthritis with Biologic Agent Therapy, during a One-Year Follow-Up
}

\author{
Asunción Acosta Pereira, Berta Magallares López, Esther Moga Naranjo, \\ Arturo Rodríguez de la Serna
}

Division of Rheumatology, Department of Internal Medicine, Hospital Sant Pau, Barcelona, Spain. Email: arodriguezs@santpau.cat

Received December $3^{\text {rd }}$, 2013; revised January $5^{\text {th }}$, 2014; accepted January $13^{\text {th }}, 2014$

Copyright (C) 2014 Asunción Acosta Pereira et al. This is an open access article distributed under the Creative Commons Attribution License, which permits unrestricted use, distribution, and reproduction in any medium, provided the original work is properly cited. In accordance of the Creative Commons Attribution License all Copyrights (C) 2014 are reserved for SCIRP and the owner of the intellectual property Asunción Acosta Pereira et al. All Copyright (C 2014 are guarded by law and by SCIRP as a guardian.

\section{ABSTRACT}

The aim of this study is to assess the variations of the RF and ACCP in RA patients treated with biologics in actual clinical practice (real) conditions for a one-year follow-up from the first biologic medication. The evaluated patients with a diagnosis of RA, according to the American College of Rheumatology (ACR) 1987 were selected from the outpatient consult of Rheumatology of the "Hospital de Sant Pau" during one month (November 2012). We collected and analyzed data from 41 patients with RA and positivity for RF and/or ACCP. Of the 41 patients had given FR and ACCP at 3, 6 and 12 months respectively in 18 and 10 patients. In 22 patients had given DAS 28 at 3, 6 and 12 months respectively. The mean age of the sample is 55 years (range 29 - 79), with a mean disease progression 9 years $(4$ months to 32 years). $70 \%$ are women. 33 patients $(80.5 \%)$ initiated treatment with antiTNF and $8(19.5 \%)$ with other no anti-TNF mechanism of action. There was a statistically significant $(p=0.001$, ANOVA) decrease in DAS 28 (average decrease of 1.6 points) at 3 months is maintained at 6 and $12 \mathrm{~m}$ and no significant differences in their evolution by separating anti-TNF drugs vs. other biological agents (different mechanisms of action $(p=0.285)$. So we have not detected a correlation between DAS 28 and FR or ACCP along the first 12 months of biological treatment. In our experience we did not find a correlation between DAS 28 and RF or ACCP, thus RF and ACCP do not appear to predict the response to treatment.

\section{KEYWORDS}

Rheumatoid Arthritis; Rheumatoid Factor; Anticitrulin Antibodies

\section{Introduction}

Rheumatoid Arthritis (RA) is a systemic inflammatory disease that is characterized for the presence of circulating antibodies. Rheumatoid Factor (RF) is an antibody that is directed against the Fc fraction of IgG, and is elevated in approximately $75 \%$ of the patients with RA [1]. Besides RF, antibodies to anti citrulinaded cyclic peptide (ACCP) are commonly observed in the sera of patients with RA and are detectable before the clinical manifestations of the disease $[2,3]$. This high specificity of ACCP, added to the frequent presence in the early disease or preclinical phase, suggest that ACCP, has an important role in pathogenesis. RF has a modest specificity in RA of $85 \%$ and a sensitivity of $65 \%-80 \%$, while ACCP appears to be more specific for RA, with $88 \%$ - $96 \%$ and a sensibility of $60 \%-80 \%$, and they are detectable even before the clinical presentation of the disease [4].

ACCP is first described in 1964, as an antibody against perinuclear factor, by Nienhuis and Mandema [5]. Young et al. detect it as an antikeratine using rat esophagus as a substrate [6]. Standardization for its detec- 
tion in the time elapsed has been complex and is in 1995 when the two antibodies described are included in the same group, reaching the conclusion that they are directed against filagrin, a constitutive protein of epitelial cells [7].

ACCP has been detected in other pathologies like psoriasis, idiopathic juvenile arthritis (IJA), multiple sclerosis, Alzheimer's and in several neoplasic diseases, all associated to the PAD enzymes and their citrulinates substrates, with differences in sensibility and specificity $[8,9]$.

Citrulination is characterized by the post-traductional modification of the amino acid arginine into the non essential amino acid citruline. This reaction is made thou enzymes called peptidil-argininea-deaminasea (PAD), this process is physiologic in the keratinization, chemo taxis, inflammation, trauma, aging, neuronal growth, embryonic development and apoptosis [10].

The enzyme PAD is constituted by five isoforms (PAD-1, 2, 3, 4 y 6) of which PAD-2 and PAD-4 have been shown to be present in the articular structure and are related to the physiology and pathology of RA, not having clear how this physiologic process, triggers a "de novo" immunologic response to antibodies, in RA developing into a pathologic process [11].

The detection of ACCP demonstrates an elevated sensitivity and specificity, predictive value, cost-effectiveness for diagnosis and early start of therapy for RA. The detection is that of ACCP IgG; but IgM and IgA, appear to be more determinant in the progress and severity of the disease. It may appear that it may be related more to a factor for worse prognosis of the disease. It has been also determined the association of the ACCP and the genetic predisposicition related to HLA of patient with RA, the shared epitope, HLA type II (HLA-DRB *0401/*0404), mutations in the gene PTPN22 [12]. Another correlation has been with the bacteria Porphyromonas gingivalis and the epidemiology of RA, and in addition generates citrulinated antigens [13].

The aim of this study is to assess the variations of the RF and ACCP in RA patients treated with biologics in actual clinical practice (real) conditions for a one-year follow-up from the first biologic medication.

\section{Materials and Methods}

\subsection{Study Design}

The evaluated patients with a diagnosis of RA, according to the American College of Rheumatology (ACR) 1987 were selected from the outpatient consult of Rheumatology of the "Hospital de Sant Pau" during one month (November 2012). Demographic data was selected in a systematic fashion, RF, ACCP, activity index of the dis- ease (DAS 28), and biologic medication type.

\subsection{Serologic Analysis}

A nephelometric method was used to determine RF. An immunoassay was used to determine ACCP. RF was considered positive if 20 or greater and for ACCP if greater than 10 in serum.

\subsection{Statistical Analysis}

For the statistical analysis of the data we have used SPSS V19.0.

The level of significance was set at a 5\% (Alfa 0.05), bilateral approximation, the analysis was carried out with the SPSS (V19.0) package.

\section{Results}

We collected and analyzed data from 41 patients with RA and positivity for RF and/or ACCP. Of the 41 patients had given FR and ACCP at 3, 6 and 12 months respectively in 18 and 10 patients. In 22 patients had given DAS 28 at 3, 6 and 12 months respectively.

The mean age of the sample is 55 years (range 29 - 79), with a mean disease progression 9 years ( 4 months to 32 years). $70 \%$ are women. 33 patients (80.5\%) initiated treatment with anti-TNF and 8 (19.5\%) with other no anti-TNF mechanism of action.

There was a statistically significant $(\mathrm{p}=0.001$, ANOVA) decrease in DAS 28 (average decrease of 1.6 points) at 3 months is maintained at 6 and $12 \mathrm{~m}$ and no significant differences in their evolution by separating anti-TNF drugs vs. other biological agents (different mechanisms of action $(\mathrm{p}=0.285)$ (Figures 1 and 2 ). Both the FR variable as in the ACCP failed to show an evolution in any of the intervals from 0 to 3 months 3 to 6 months, or 6 to 12 months $(\mathrm{p}=0.12, \mathrm{p}=0.09, \mathrm{p}=$ 0.173 respectively. Wilcoxon). So we have not detected a correlation between DAS 28 and FR or ACCP along the first 12 months of biological treatment.

\section{Discussion}

The ACCP (antibodies anticitrulinated protein), are a class of antibodies directed to one or more protein.

ACCP is described as first, second, or third generation: CСP 1, CCP 2 y CCP 3, respectively). Since their development in 2002, the second generation is used more often.

For RA, ACCP 2, has a greater sensibility than ACCP1 (77\% versus 68\%) with a similar specificity (95\% versus $96 \%$ ) for the diagnosis of RA with respect to other artcular disease and $99 \%$ with respect to a healthy population without evidence of articular pathology [14]. 


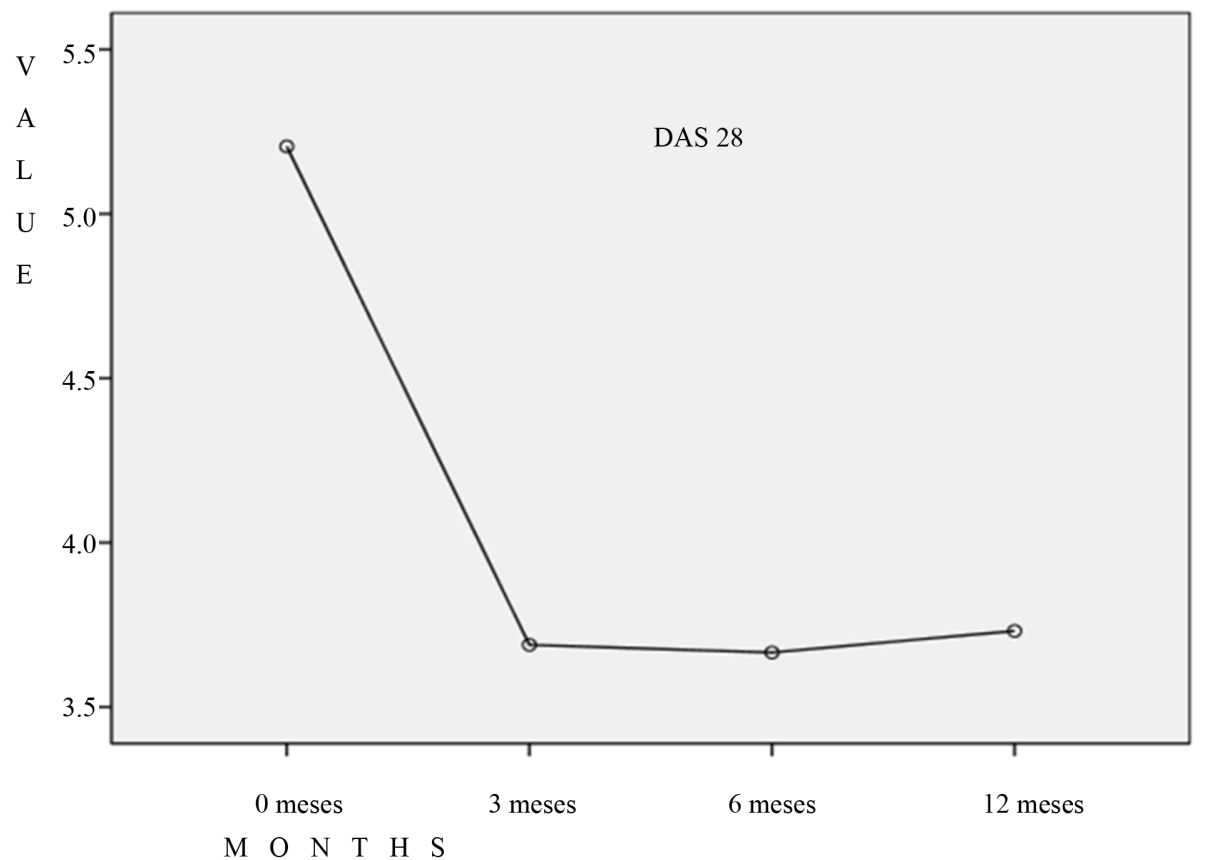

Figure 1. There was a statistically significant $(p=0.001$, ANOVA) decrease in DAS 28 (average decrease of 1.6 points) at 3 months is maintained at 6 and 12m,with anti-TNF therapy.

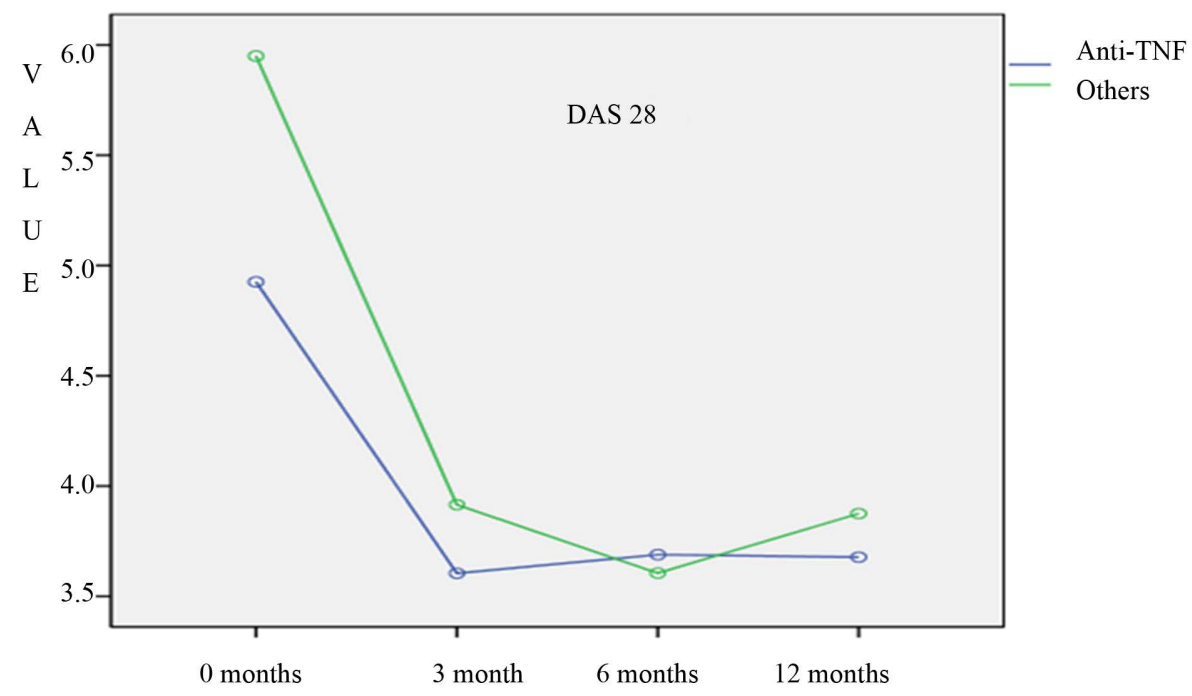

Figure 2. decrease in DAS 28 (average decrease of 1.6 points) at 3 months is maintained at 6 and 12 m and no significant differences in their evolution by separating anti-TNF drugs vs. other biological agents $(p=0.285)$.

Citrulinated antigens exist in the serum of patients with RA and they associate with a treatment response like:

1) Alfa enolase (CEP-1 aminoácids 4 - 21).

2) Vimentina (cVim amino acidos 60 - 75).

3) beta chain Fibrinogen.

Citrulinated Vimentine (MCV) is an autoantibody to be studied in RA, with the possibility that these antibodies be useful for the follow up of the therapy for RA.
The proteins that normally contain residues of citruline are: myelin basic protein (MBP), filagrin and several histone proteins, while other proteins like fibrin and Vimentinonly acquire the citrulin component during cell death and inflammation of the tissue. Fibrin and fibrinogen can be favored sites, for the deamination of arginine inside the joints of rheumatoid joints [12].

Anti CEP-1 in addition to Vim are important factors from the genetically and environmental point of view for 
RA. Antibodies to CEP-1, C-Vim-cFib are positive in RA at $39 \%, 42 \%$ y $75 \%$, showing then that anti cFib, that is more frequent has proven to have an association with a smaller response as defined by DAS28 at 6 month, been an indicator of poor response of antiTNF alpha in RA; but neither the anti CEP-1 and C-Vim that are associated with HLA DRB1 nor it epitope, nor PTPN 22 predict the response to anti $\mathrm{TNF}$ ( not associated to poor response or no response); nevertheless anti cFib is present in a high frequency in patients with antibody to anti CCP2 and relates to a high response. HLA associations and other genetic and environmental risk factors are added in diseases ACPA positive [15-19]. What has been tried during the last few years is overall correlate ACCP with some factor, so from the etiologic point of view, one could be able to correlate with the development of RA.; Establishing debates of multifactorial causes were ACCP is implicated with pathogenesis.

What we do have in the review of the literature is 54 diagnostic studies and 39 prognostic studies that take in consideration the ACCP.

Dejaco in 2010, in his article [20], described that the levels of ACCP2 and ACCP3 were not modified after six months of anti TNF treatment neither could they be correlated with the response to therapy. Nonetheless, in another study [21] it was concluded that subtype IgG4 of ACCP, was modified to a lesser lever, after receiving treatment with infliximab, and the authors suggest a possible beneficial effect of the antiTNF in the chronic antigenic stimulation though the depletion of these antibodies.

When we talk of prognosis and response to biologic treatment of patient with RA, we can establish if it is worst o better, the characteristics that allow to correlate are IgG A, RF, high ACCP, high index of disease function (HAQ) and a disease with a erosive structural damage at the beginning of it, all that correlates with a worse response to therapy and a poor prognosis [22-24].

Some studies have demonstrated with patients treated with biologic therapy anti TNF, are reduced in a significative way the ACCP IgG with disease remission [24]. This was demonstrated in our study concluding that the patients with ACCP positive and RF positive achieve improvement of the activity of the disease with a significant lowering of the DAS28.

In our opinion, it is not clear o there is no correlation of neither the RF, nor of the ACCP, with the index of DAS28 activity in the follow up of our patients that receive biologic treatments.

One possible explanation would be the necessity of a larger number of patients, since this is a preliminary study and one could be able reach that simple.

Another possible explanation is that probably could be present other citrulinates with a marked association with poor or better response to therapy or that the ACCP and RF test has a limited capacity to detect multiple specificities of AR itself, without the modification RF or the ACCP.

The negative correlation between DAS28, RF and ACCP in our study could define that even though RF and ACCP are used with a diagnostic value, described in other clinical studies, it potential utility as markers for the prognosis, understood as radiological damaged and DAS28 is nule, then it could be considered contradictory those data and to designate RF and ACCP like parameters for follow up, we need to understand and do mover studies of a more prolonged follow up.

\section{Conclusion}

In our experience we did not find a correlation between DAS 28 and RF or ACCP, thus RF and ACCP do not appear to predict the response to treatment.

\section{Acknowledgements}

We gratefully acknowledge to Dr. Gary Sterba, Medical Consult, Miami, for you manuscript reviewing

\section{REFERENCES}

[1] R. Schrohenloher, S. J. Bridges and W. Koopman, "Rheumatoid Factor,” In: W. J. Koopmamn, Ed., Arthritis and Allied Conditions. A Textbook of Rheumatology. 13th Edition, Vol. 1, Willians \& Wilkins, Baltimore, 1996, pp. 1109-1130.

[2] G. A. Schellekens, B. A. de Jong, F. Van den Hoogen, L. van de Putte and W. van Venrooij, "Citrulline Is an Essential Constituent of Antigenic Determinants Recognized by Rheumatoid Arthritis-Specific Autoantibodies," Journal of Clinical Investigation, Vol. 101, No. 1, 1998, pp. 273-281.

[3] G. A. Schellekens, H. Visser, B. A. de jong, F. H. Van de Hoogen, J. M. Hazes, F. C. Breedveld, et al., “The Diagnosis Propietiers of Rheumatoid Arthritis Antibodies Recognizing a Cyclic Citrullinated Peptide,” Arthritis \& Rheumatology, Vol. 43, No. 1, 2000, pp. 155-163. http://dx.doi.org/10.1002/1529-0131(200001)43:1<155:: AID-ANR20>3.0.CO;2-3

[4] M. M. Nielen, D. Van Schaardenburg, H. W. Reesink, R. J. Van de Stadt, I. E. Van der Horst-Bruinsma, M. H. de Koning, et al., "Specific Autoantibodies Precede the Symptoms of Rheumatoid Arthritis. A Study of Serial Measurement in Blood Donors,” Arthritis \& Rheumatology, Vol. 50, No. 2, 2004, pp. 380-386. http://dx.doi.org/10.1002/art.20018

[5] J. S. Smolen, A. Beauilieu, A. Rubbert-Rocth, C. RamosRemus, J. Rovensky, et al., "Effect of Interleukin-6 Receptor Inhibition with Tocilizumab in Patients with Rheumatoid Arthritis (OPTION Study) a Double-Blind Placebo Controlled Randomised Trial," Lancet, Vol. 37, No. 
9617, 2008, pp. 987-997.

http://dx.doi.org/10.1016/S0140-6736(08)60453-5

[6] J. M. Kremer, A. S. Russel, P. Emery, C. Abud-Mendoza, J. Szechinski, R. Westhovens, et al., "Long-Term Efficacy an Inhibition of Radiographic Progression with Abatacept Treatment in Patients with Rheumatoid Arthritis and an Inadequate Response to Methotrexate: 3 Years Results from the AIM Trial," Annals of the Rheumatic Diseases, Vol. 70, No. 10, 2011, pp. 1826-1830. http://dx.doi.org/10.1136/ard.2010.139345

[7] M. Sebbag, M. Simon, C. Vincent, et al., "The Anti-Perinuclear Factor ant the So-Called Anti-Keratin Antibodies Are the Same Rheumatoid Arthritis-Specific Autoantibodies,” Journal of Clinical Investigation, Vol. 95, No. 6, 1995, pp. 2672-2679.

http://dx.doi.org/10.1172/JCI117969

[8] T. Senshu and G. Serre, “The Major Synovial Targets os the Rheumatoid Arthritis-Specific Anti-Filaggrin Autoantibodies Are Delaminated Forms of the Alpha and Beta-Chains os Fibrin,” Journal of Immunology, Vol. 66, 2001, pp. 4177-4184.

[9] A. Ishigami and N. Maruyama, "Importance of Research on Peptidylarginine Deiminase and Citrullinated Proteins in Age-Related Disease,” Geriatrics \& Gerontology International, Vol. 10, Suppl. 1, 2010, pp. S53-S58.

[10] D. M. Lee and P. H. Schur, "Clinical Utility of the Anti CCP Assay in Patient with Rheumatoid Disease," Annals of the Rheumatic Diseases, Vol. 62, No. 9, 2003, pp. 870874. http://dx.doi.org/10.1136/ard.62.9.870

[11] A. Suzuki, R. Yamaha, X. Chang, S. Tokuhiro, T. Sawed, M. Suzuki, et al., "Functional Heliotypes of PAD14, Eroding Citrullinating Enzyme Peptidylarginine Deiminase 4, Are Associated with Rheumatoid Arthritis," Nature Genetics, Vol. 34, 2003, 395-402. http://dx.doi.org/10.1038/ng1206

[12] K. N. Verpoort, C. M. Jol-van der Zijde, E. A. M. Papendrecht-van der Voort, A. Ioan Facsinay, J. W. Drijfhout and M. J. Van Tol, "Isotype Distribution of Anti Cyclic Citrullinnated Peptide Antibodies un Indifferentiated Arthritis and Rheumatoid Arthritis Reflects an Ongoing Immune Response,” Arthritis \& Rheumatology, Vol. 54, No. 12, 2006, pp. 3799-3808.

http://dx.doi.org/10.1002/art.22279

[13] P. De Pablo, I. L. C. Chspple, C. D. Buvkely and T. Dietrich, "Periodonditis in Systemic Rheumatic Disease," Nature Reviews Rheumatology, Vol. 5, No. 4, 2009, pp. 218-224.

[14] B. A. Fisher, D. Plant, K. Lundberg, P. Charles, A. Barton and P. J. Venables, "Heterogeneity of Citrullinated Peptide Antibodies and Response to Anti-Tumor Necrosis Factor Agents in Rheumatoid Arthritis," Journal of Rheumatology, Vol. 39, No. 5, 2012, pp. 929-932. http://dx.doi.org/10.3899/jrheum.111315

[15] H. Mahdi, B. A. Fisher, H. Källberg, D. Plant, V. Malmström, J. Rönnelid, et al., "Specific Interaction between Genotype, Smoking and Autoimmunity to Citrullinated Alpha-Enolase in the Etiology of Rheumatoid Arthritis," Nature Genetics, Vol. 41, 2009, pp. 1319-1324.

\section{http://dx.doi.org/10.1038/ng.480}

[16] D. van der Woude, W. G. Alemayehu, W. Verduijn, R. R. de Vries, J. J. Houwing-Duistermaat, T. W. Huizinga, et al., "Gene-Environment Interaction Influences the Reactivity of Autoantibodies to Citrullinated Antigens in Rheumatoid Arthritis," Nature Genetics, Vol. 42, 2010, pp. 814-816. http://dx.doi.org/10.1038/ng1010-814

[17] K. N. Verpoort, K. Cheung, A. Ioan-Facsinay, A. H. van der Helm-van Mil, J. K. de Vries-Bouwstra, C. F. Allaart, et al., "Fine Specificity of the Anti-Citrullinated Protein Antibody Response Is Influenced by the Shared Epitope Alleles," Arthritis \& Rheumatology, Vol. 56, No. 12, 2007, pp. 3949-3952. http://dx.doi.org/10.1002/art.23127

[18] C. Potter, K. L. Hyrich, A. Tracey, M. Lunt, D. Plant, D. P. Symmons, et al., "Association of Rheumatoid Factor and Anti-Cyclic Citrullinated Peptide Positivity, but Not Carriage of Shared Epitope or PTPN22 Susceptibility Variants, with Anti-Tumour Necrosis Factor Response in Rheumatoid Arthritis," Annals of the Rheumatic Diseases, Vol. 68, No. 1, 2009, pp. 69-74. http://dx.doi.org/10.1136/ard.2007.084715

[19] N. Wegner, K. Lundberg, A. Kinloch, B. Fisher, V. Malmström, M. Feldmann, et al., "Autoimmunity to Specific Citrullinated Proteins Gives the First Clues to the Etiology of Rheumatoid Arthritis," Immunological Reviews, Vol. 233, No. 1, 2010, pp. 34-54. http://dx.doi.org/10.1111/j.0105-2896.2009.00850.x

[20] C. Dejaco, C. Duftner, W. Klotz, M. Schirmer and M. Herold, "Third Generation Anti-Cyclic Citrullinated Peptide Antibodies Do Not Predict Anti-TNF. Alfa Treatment Response in Rheumatoid Arthritis,” Rheumatology International, Vol. 30, No. 4, 2010, pp. 451-454. http://dx.doi.org/10.1007/s00296-009-0978-4

[21] W. H. Bos, G. M. Bartelds, M. Vis, A. R. van der Horst, et al., "Preferential Decrease in IgG4 Anti-Citrullinated Protein Antibodies during Treatment with Tumor Necrosis Factor Blocking Agents in Patients with Rheumatoid Astrhitis,” Annals of the Rheumatic Diseases, Vol. 68, No. 4, 2009, pp. 558-563. http://dx.doi.org/10.1136/ard.2008.088401

[22] S. Rantapaa-Dahlqvist, B. A. W. De Jong, E. Berglin, et al., "Antibodies against Cyclic Citrullined Peptide and IgA Rheumatoid Factor Predict the Development of Rheumatoid Arthritis," Arthritis \& Rheumatology, Vol. 48, No. 10, 2003, pp. 2741-2749.

http://dx.doi.org/10.1002/art.11223

[23] F. Bobbio-Pallavicini, R. Caporali, C. Alpini, R. Moratti and C. Montecucco, "Predictive Value of Antibodies to Citrullined Peptides and Rheumatoid Factors in Anti TNF Alpha Treated Patients," Annals of the New York Academy of Sciences, Vol. 1109, 2007, pp. 287-295. http://dx.doi.org/10.1196/annals.1398.034

[24] L. Mancarella, F. Bobbio-Pallavicini, F. Ceccarelli, P. C. Falappone, A. Ferrante, D. Malesci, et al., "Good Clinical Response, Remission, and Predictors of Remission in Rheumatoid Arthritis Patients Treated with Tumor Necrosis Factor-Alpha Clockers: The GISEA Study,” Journal of Rheumatology, Vol. 34, 2007, pp. 1670-1673. 